\title{
Culture and achievement motivation
}

\author{
Martin L. Maehr \\ University of Michigan, Ann Arbor, USA
}

Keywords: Achievement motivation; Asian; Culture; Social constructivist.

This symposium and the papers that compose it reflect the fact that the study of culture and achievement motivation has truly "come of age." Gone are the days when a few hearty souls from Europe, Great Britain, the United States, and Australia, as well as a few others imbedded in the research traditions largely associated with "Western oriented centres of knowledge" stood as the primary source for prompting and guiding research on the nature and nurture of motivation. Equally, if not more, important is that studies of culture and motivation are increasingly conducted under the purview of a multicultural community of scholars. Certainly, this represents an exciting development, and the papers that compose this symposium are interesting as they provide fresh perspectives on motivation as it emerges in contexts and cultures not often portrayed in the motivation literature in the so-called "Western world."

While the scholars who have contributed to this symposium reflect an awareness of the research traditions of the past, they also exhibit special insights into the uniqueness of the varied cultures they have studied, the meanings of motivation that are associated with these cultures and the varied impact of these meanings on ways of acting and thinking.

Certainly, this all speaks well for the level of scholarship evident in these papers. It also holds out the promise that the study of culture and motivation is neither dormant nor outmoded. Permit me, however, to raise an issue that I am regularly inclined to raise with the motivation research community in the United States. From the outset, the study of achievement motivation has largely followed in the tradition that was initiated and established by David McClelland (e.g., 1961, 1985). Not in all respects, to be sure. Certainly, the work reported in this symposium hardly features the use of the Thematic Apperception Test (TAT) as the sine qua non for assessing achievement motivation. Rather, it reflects an extensive use of sociocognitive and/or self-report measures of motivation-and largely treats these as durable characteristics of the person, therewith often paying only incidental attention to the role of context in prompting and shaping the action that leads to the inference that a person is or is not "motivated." Of course, that is largely the case also with the work reported by scholars in the Western world as well, although there is currently an emergent tendency for many researchers, especially those concerned with applications in school settings, to adopt a more situated or social constructivist perspective vis-à-vis motivation and achievement (e.g., Hickey, 1997; Turner \& Meyer, 1999). And, I would suggest, that there is a need to consider motivation as a process rather than a trait.

There are multiple reasons for proposing this. Many years ago, I suggested one of these (Maehr, 1974). Reviewing the way in which teachers, employers and also researchers thought of motivation, namely as an acquired and durable personality characteristic of the individual, I proposed that more attention ought to be given to the context as perceived and experienced by the "potential achiever": student, employee, or athlete. I arrived at this rather simple notion by first observing the behaviour of children enrolled in public schools in a large metropolitan area. The

Correspondence should be addressed to Professor Martin Maehr, Department of Psychology, University of Michigan, 1012 East Hall, 530 Church Street, Ann Arbor, MI 48109-1043, USA. (E-mail: mlmaehr@umich.edu). 
operative description of the time was that the children were "culturally deprived" such that they simply did not, would not, or perhaps could not, exhibit any energy, focus, or effort - at least in the classroom. Of course, all that one would have to do is to visit these children in their own neighbourhoods, on the basketball courts, engaging in "business" (not necessarily legal) transactions on the streets, to realize that they had considerable motivation and in many respects exhibited the motivational characteristics of successful entrepreneurs. They exhibited the moderate risk-taking, the energy, the persistence, and the drive that McClelland (e.g., 1961, 1985) portrayed as the "achieving spirit" so important to the emergence of the "achieving society" anticipated by Max Weber (1904/1930) and portrayed more fully and analytically by McClelland (1961).

Reflecting on multiple observations of children in classrooms, on school grounds, or in out-ofschool settings of importance to them it became clear to me that psychologists may well be spending too much time on measuring individual differences on a variety of motivation assessment instruments, be they the TAT or self-report questionnaires of one variety or another. Rather, more attention should be give to systematically gathering information on how contexts-who composes them, as well as the purposes that guide them - play an important role in whether or how individuals engage, invest, persist, and produce. In other words, achievement motivation is largely social psychological in nature. It often occurs within groups, where interpersonal interactions can undermine or facilitate engagement in the tasks to be done. One can learn from others, but others may also undermine the best of one's intentions. As a group phenomenon, social comparisons are inevitable and may or may not be facilitative: Social contexts may raise hopes as well as undermine aspirations. I suggest that that one task for the future is to take account of the interpersonal nature of achievement motivation in different venues and varying cultures. From time to time, cross-cultural research of the past did pay considerable attention to interpersonal interactions. Indeed, this was often a major feature of anthropological studies. I propose here a somewhat scaled down and social psychological consideration of the interpersonal side of achievement motivation across varying cultures and contexts. The papers such as those that prompted my reflections have provided a rich and fruitful basis for expanding the consideration of the varying nature of achievement motivation as it occurs from place to place and within this or that achievement setting.

\section{REFERENCES}

Hickey, D. T. (1997). Motivation and contemporary socio-constructivist instructional perspectives. Educational Psychologist, 32, 175-193.

Maehr, M. L. (1974). Culture and achievement motivation. American Psychologist, 29, 887-896.

McClelland, D. C. (1961). The achieving society. Princeton, NJ: Van Nostrand.

McClelland, D. C. (1985). Human motivation. Chicago: Scott Foresman.

Turner, J. C., \& Meyer, D. K. (1999). Integrating classroom context into motivation theory and research: Rationales, methods, and implications. In T. Urdan, M. Maehr, \& P. R. Pintrich (Eds.), Advances in motivation, Vol.11 (pp.87-121). Greenwich, CT: JAI Press.

Weber, M. (1930). Die protestantische Ethik und der Geist des Kapitalismus [The Protestant ethic and the spirit of Capitalism, first published 1904]. In T. T. Parsons (Ed.), Archiv fur Sozial Wissenschatt und Sozial Politik; 1904, 1905 (Vol. 20, 1-54; Vol.21, 1110). New York: Scribner. 